\title{
Evolução Sedimentar Miocênica nos Estados do Pará e Maranhão
}

\author{
Dilce de Fátima Rossetti (rossetti@dsr.inpe.br) \\ Centro de Observação da Terra - Divisão de Sensoriamento Remoto - INPE \\ R. dos Astronautas 1758, CEP 12245-970, São José dos Campos, SP, BRA \\ Recebido em 27 de dezembro de 2005; aceito em 14 de junho de 2006
}

Palavras-chave: Mioceno, Norte do Brasil, estratigrafia, paleoambientes.

\section{RESUMO}

Depósitos miocênicos, designados litoestratigraficamente de formações Pirabas e Barreiras, acham-se bem expostos no nordeste do Pará e litoral do Maranhão, onde são representados por uma variedade de fácies carbonáticas a siliciclásticas. A grande maioria das fácies carbonáticas e mistas carbonático-siliciclásticas teve sua origem em ambiente variando entre marinho transicional a plataformal. Estes depósitos acham-se internamente organizados em três sucessões estratigráficas definidas por superfícies de descontinuidade mapeáveis em escala regional. A análise destas superfícies, combinada com as características faciológicas e seus padrões estratais, sugere formação em sistemas de vales estuarinos incisos, com deposição descontínua devido à influência de episódios múltiplos de variação do nível do mar de alta freqüência superpostos a uma tendência geral transgressiva a mar alto. $\mathrm{O}$ estabelecimento e a evolução deste sistema de paleovales estuarinos ocorreram após um intervalo de aproximadamente 40 milhões de anos de não deposição e/ou erosão e foram, mais provavelmente, resultantes da combinação de fatores eustáticos com reativações tectônicas. A forma de abordagem empregada nos estudos dos estratos miocênicos expostos nos estados do Pará e Maranhão, integrando análise faciológica, arquitetura estratal, mapeamento de superfícies estratigráficas chaves e icnologia, pode servir para orientar estudos futuros enfocando depósitos similares em outras áreas do território nacional.

Keywords: Miocene, northern Brazil, stratigraphy, paleoenvironments.

\section{ABSTRACT}

Miocene deposits, lithostratigraphically designated as the Pirabas and Barreiras formations, are well exposed in northeastern State of Pará and along the coastline of the State of Maranhão, where they are represented by a variety of sedimentary facies ranging from limestones to siliciclastics. The majority of the limestones and mixed limestone to siliciclastic deposits were formed in environments ranging from marine transitional to shelf. These deposits are internally organized into three stratigraphic successions defined by regional discontinuity surfaces. Analysis of these surfaces, combined with facies characteristics and stratal patterns, suggests an incised valley estuarine system with discontinuous deposition due to multiple episodes of highfrequency relative sea level fluctuations superimposed on an overall transgression to highstand. The establishment and evolution of this incised valley estuarine system occurred after an interval of up to $40 \mathrm{Ma}$ of non-deposition and/or erosion, and probably resulted from eustatic fluctuations combined with tectonic reactivation. Based on the results obtained for the Miocene deposits exposed in the states of Pará and Maranhão, it is proposed that studies combining facies analysis, ichnology, stratal architecture, and mapping of key stratigraphic surfaces might be profitably applied to similar deposits elsewhere in Brazil. 


\section{INTRODUÇÃO}

O Mioceno foi um período geologicamente ativo, tendo testemunhado eventos como expansão de geleiras na Antártida, fechamento do Mar Mediterrâneo e soerguimentos importantes em vários cinturões orogênicos de grande repercussão global. Estas mudanças definiram a transição para o mundo moderno, sendo, portanto, de grande interesse nos diferentes campos das ciências. Se, por um lado, o registro geológico miocênico é, em geral, abundante, sua correlação estratigráfica é ainda problemática em diferentes regiões do globo (Montanari et al., 1997). No Brasil, exposições de depósitos desta idade são, em grande parte, representadas pela Formação Barreiras, cuja distribuição dá-se ao longo de uma estreita faixa na zona litorânea, desde o Amapá até o Rio de Janeiro. Apesar da ampla distribuição geográfica, o detalhamento destes depósitos é, ainda, inadequado à formulação de modelos paleoambientais e, principalmente, à sua correlação em escala continental. Esta situação pode ser atribuída, em parte, ao acentuado intemperismo, à natureza descontínua, e à carência de informações paleontológicas. Porém, o reduzido interesse econômico destes depósitos tem sido o fator determinante do baixo volume de estudos sistemáticos que possibilitem o detalhamento sedimentológico e estratigráfico necessário à reconstituição dos eventos miocênicos no Brasil.

A região nordeste do Estado do Pará e o litoral do Maranhão apresentam um extenso registro miocênico (Figura 1), favorecido excepcionalmente pela preservação de abundantes estruturas sedimentares. Além disto, estes depósitos, representados pelas formações litoestratigráficas Pirabas e Barreiras, mostram características estratigráficas que têm permitido o estabelecimento de critérios de correlação em escala regional. Uma abordagem sistemática, conduzida nos últimos 15 anos, tem levado à proposição de que a gênese dos estratos miocênicos desta região do país está associada com mecanismos alóctones, envolvendo fatores ligados principalmente com variações do nível do mar, movimentações tectônicas e flutuações climáticas (Rossetti 2000, 2001, 2006; Rossetti e Santos Jr., 2004). Modelos paleoambientais e estratigráficos resultantes destes trabalhos podem servir para motivar e orientar estudos sistemáticos em várias outras localidades da costa brasileira, com ocorrência de estratos similares aos encontrados nas formações Pirabas e Barreiras que ocorrem nos estados do Pará e Maranhão.

Neste trabalho, apresenta-se uma síntese da evolução sedimentar proposta para os depósitos miocênicos expostos no nordeste do Pará e litoral do Maranhão. Não é intenção apresentar aqui, de forma exaustiva, as características faciológicas e estratigráficas desta sucessão, o que já foi feito em detalhe em outros trabalhos. A presente publicação se presta, no entanto, para compor a base de dados dos eventos miocênicos do Brasil referentes a esta publicação especial sobre a Formação Barreiras. Espera-se, com isto, fornecer o estado-da-arte referente ao registro destes depósitos em áreas da região norte e meio-norte do Brasil e, principalmente, apresentar sugestões de abordagem sedimentológica e estratigráfica que possibilitem melhorar a compreensão das condições de deposição destes estratos e sua correlação dentro do território nacional.

\section{ARCABOUÇO GEOLÓGICO}

Os depósitos miocênicos nos estados do Pará e Maranhão, tradicionalmente referidos de formações Pirabas (Neo-Oligoceno/Eomioceno) e Barreiras (Meso a Neomioceno), ocorrem em diferentes contextos estruturais, sendo particularmente bem expostos no norte da Bacia de São Luís, centro-leste da sub-bacia de Cametá na porção leste do Sistema de Graben do Marajó, Bacia de Bragança-Vizeu, e nas plataformas Bragantina e do Pará (Figura 1).

As bacias de São Luís, Cametá e Bragança-Vizeu representam estruturas alongadas na direção noroeste-sudeste, cujas gêneses estão vinculadas a estiramento litosférico relacionado com a abertura do Oceano Attântico Equatorial, iniciado no Eocretáceo (p.ex., Azevedo, 1991; Galvão, 1991; Góes e Rossetti, 2001). Os processos tectônicos nestas bacias mostraram-se efetivos não só durante o tempo da fragmentação principal, mas permaneceram ativos durante o Cretáceo e Cenozóico (Costa e Hasui, 1997; Costa et al., 1993, 1996, 2002). No Mioceno, destaca-se o desenvolvimento de tectonismo em regime de transcorrência, refletido em falhas normais NW-SE e transcorrentes E-W e NE-SW (Costa et al., 1993, 1995; Hasui, 1990; Costa et al., 1996; Ferreira Jr. et al., 1996), que têm continuidade até o Recente. (Bermeguy e Costa, 1991; Bermeguy, 1997; Igreja et al., 1990; Igreja, 1992; Costa et al., 1996).

As plataformas Bragantina e do Pará correspondem a áreas do embasamento que permaneceram tectonicamente estáveis entre as bacias sedimentares. A Plataforma do Pará corresponde a uma ampla área ainda pouca explorada que engloba a porção leste da Ilha do Marajó, estendendo-se costa afora, onde é interceptada pela Fossa Vigia-Castanhal.

\section{HISTÓRICO E DEFINIÇÃO DO TERMO “BARREIRAS"}

As primeiras referências sobre os depósitos miocênicos na região norte do Brasil são bastante remotas (Penna, 1876; Carvalho, 1926; Katzer, 1933; Oliveira e Leonardos, 1943). A carência de estudos sedimentológicos e estratigráficos detalhados dificultaram, por muitos anos, a determinação da relação entre as unidades litoestratigráficas designadas de Pirabas e Barreiras. De forma geral, estes estratos foram 


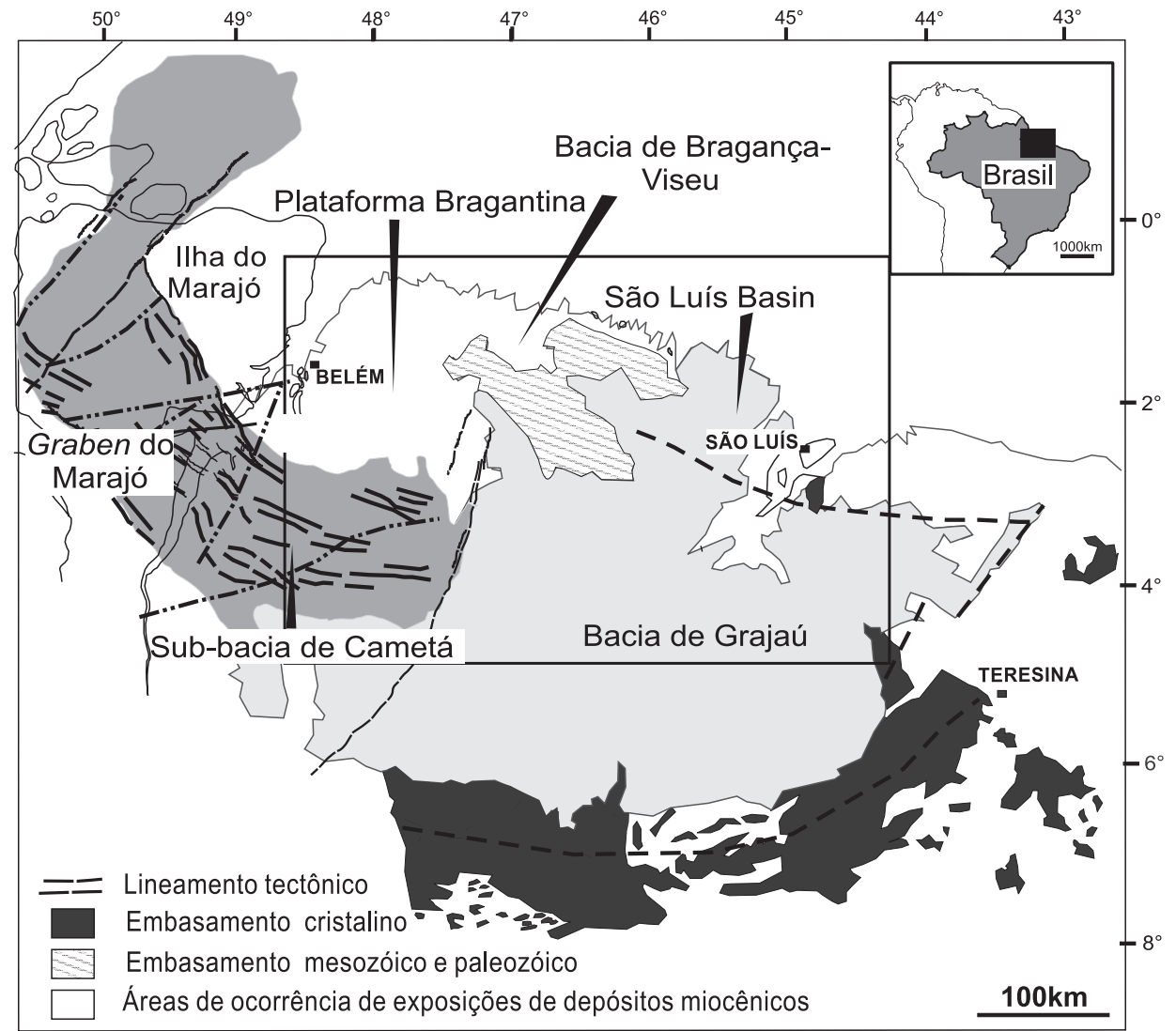

Figura 1. Mapa de localização das bacias sedimentares e plataformas na região norte do Brasil que possuem exposições de depósitos miocênicos.

tradicionalmente considerados como geneticamente nãorelacionados, sendo o termo Formação Pirabas empregado para a sucessão carbonática contendo intercalações secundárias de folhelhos negros a esverdeados e arenitos amarelados (Petri, 1954, 1957; Ferreira, 1966), e Formação Barreiras utilizado para o conjunto sedimentar superposto, caracterizado genericamente por depósitos siliciclásticos de cores variegadas (Sá, 1969).

Enquanto o rico e variado conteúdo fossilífero permitiu o estabelecimento de idade oligocênica/miocênica para a Formação Pirabas, com base principalmente na presença do gastrópode Orthaulax pugnax (Ferreira, 1982) e de foraminíferos (Petri, 1954, 1957; Fernandes, 1984; Ferreira et al., 1984), a Formação Barreiras foi, por muito tempo, atribuída ao Plioceno/Pleistoceno, por correlação com depósitos homônimos que ocorrem no nordeste brasileiro (Mussa, 1958; Amador, 1982). Entretanto, informações palinológicas possibilitaram constatar que a deposição desta unidade foi mais antiga, em grande parte ocorrida no Mioceno Médio (Arai et al., 1988; Arai, 1997; Leite et al., 1997a, 1997b). Estes da- dos, juntamente com interpretações faciológicas, permitiram inferir, ainda, influência marinha na deposição dos litotipos da Formação Barreiras (Rossetti et al., 1989, 1990), o que levou à sugestão de interdigitação desta com a Formação Pirabas (Arai et al., 1988; Góes et al., 1990), reforçando sugestões anteriores já apresentadas na literatura (p.ex., Arantes et al., 1972).

Nestas duas últimas décadas, ênfase passou a ser dada para a análise da arquitetura de fácies em associação com o reconhecimento de superfícies estratigráficas-chaves como parâmetro de correlação dos estratos miocênicos (e.g., Rossetti, 2000, 2001, 2006; Rossetti e Santos Jr., 2004; Rossetti, 2004; Rossetti e Góes, 2004), o que se revelou fundamental na identificação de unidades estratigráficas contemporâneas que se prestassem à elaboração de modelos deposicionais mais consistentes. Este procedimento foi importante para se demonstrar que as formações Pirabas e Barreiras formam uma sucessão geneticamente relacionada, ligada ao desenvolvimento de uma mesma seqüência deposicional, que resultou na gradação de estratos 
carbonáticos-siliciclásticos para totalmente siliciclásticos ao longo da evolução miocênica. Emprega-se aqui, portanto, o termo Pirabas/Barreiras para se referenciar ao conjunto miocênico exposto nos estados do Pará e Maranhão, definido, na base e topo, por discordâncias com caráter erosivo e marcadas e/ou correlacionáveis com paleossolos lateríticos mapeáveis em escala regional. Dada a relação genética existente entre as formações Pirabas e Barreiras, sua análise deve ser conduzida em conjunto.

\section{FÁCIES E AMBIENTE DEPOSICIONAL}

Os estratos miocênicos nos estados do Pará e Maranhão ocorrem em afloramentos descontínuos expostos ao longo de falésias costeiras, bem como em cortes de estradas e minas de caulim a céu aberto. Ocorrências menores são registradas também no norte do Estado do Piauí, a leste da desembocadura do Rio Parnaíba (Ferreira, 1964). Estes depósitos consistem em uma variedade de fácies carbonáticas e siliciclásticas.

As fácies carbonáticas mostram proporções variáveis de grãos siliciclásticos, consistindo em biocalcirruditos estratificados e não-estratificados, margas, calcilutitos e bioermitos. Litologias dominantes são wackestonegrainstone fossilífero, rudstones-floatstones-mudstones e dolomitos neomorfizados. Grãos esqueletais incluem vários tipos de invertebrados, representados por equinodermas, gastrópodes, foraminíferos (plantônicos e bentônicos), ostracodes, bivalves, briozoários, algas (vermelhas e, subordinadamente, verdes) e raras calcisferas. As fácies siliciclásticas consistem em arenitos quartzosos, depósitos heterolíticos, argilitos e, menos comumente, conglomerados de colorações negra, verde oliva, cinza ou, ainda, variegada (i.e., violácea, amarelada a avermelhada).

Um passo importante para a reconstituição do sistema deposicional da sucessão Pirabas/Barreiras foi o reconhecimento de estruturas atribuídas à influência de maré nas porções siliciclásticas (Figuras 2A a 2F). Estas compreendem estratificações cruzadas contendo sucessões de foresets arranjados em pacotes alternadamente mais espessos e mais delgados e separados por superfícies de reativação e/ou filmes de argila formando pares (Figuras 2A e 2B), além de paleocorrentes com distribuição bidirecional (Figura 2C). Adicionalmente, vários tipos de depósitos heterolíticos acham-se presentes (Figura 2D), sendo que estes localmente apresentam variações cíclicas, formando pacotes de areia alternadamente mais delgados e espessos que agradam sucessivamente, intercalando-se ritmicamente com lâminas de argila, também caracterizando pares (Figura 2E). Estas feições sedimentares são associadas a flutuações de velocidade de correntes de maré (Rossetti et al., 1989, 1990; Rossetti 2000, 2001; Rossetti e Santos Jr., 2004). Sendo assim, a análise faciológica na sucessão siliciclástica, correspon- dente em grande parte à Formação Barreiras, resultou no reconhecimento de depósitos atribuídos a vários ambientes litorâneos dominados por correntes de maré (Arai et al., 1988; Rossetti et al., 1989, 1990; Rossetti, 2000; Rossetti e Santos Jr., 2004). Para o pacote carbonático e carbonáticosiliciclástico associado atribui-se origem em ambiente marinho-transicional a plataformal (Góes et al., 1990).

Embora carente em fósseis, a sucessão miocênica siliciclástica em questão mostra-se bastante rica em icnofósseis (Figuras 2F, 2G e 2H), que se constituem em elementos auxiliares na caracterização paleoambiental. Assim, os icnofósseis presentes, incluindo-se Thalassinoides, Ophiomorpha, Skolithos, Gyrolithes, Planolites, Diplocraterion, Taenidium, Psilonichnus, Palaeophycus, Teichichnus, Chondrites, Rhizocorallium, Phycosiphon e Cylindrichnus, definem assembléias empobrecidas típicas de ambientes mixoalinos ou marinho-transicionais (Góes et al., 1990; Távora e Silva, 2001; Netto e Rossetti, 2003; Rossetti e Santos Jr., 2004).

Apesar da extensa área de ocorrência, os depósitos miocênicos expostos no nordeste da Amazônia podem ser sumariados em termos de um modelo deposicional único, que mais possivelmente inclui um complexo de vales incisos estuarinos (Rossetti, 2000, 2001; Figura 3). A natureza estuarina é destacada com base na abundância de depósitos formados por processos de maré, na variedade de ambientes deposicionais típicos de sistemas estuarinos incluindo-se abundantes canalizações, no relacionamento com estratos atribuídos à plataforma rasa e plataforma restrita, $\mathrm{e}$ na associação icnológica com representantes de ambientes litorâneos estressantes e com influência de água salobra. A atribuição destes depósitos estuarinos a vales incisos dáse em função de depósitos estuarinos se constituírem nos principais componentes do preenchimento sedimentar de vales incisos (Zaitlin et al., 1994).

\section{EVOLUÇÃO ESTRATIGRÁFICA}

Os estratos miocênicos dos estados do Pará e Maranhão revelam organizações estratigráficas bastante similares, apesar da ocorrência em compartimentos tectônicos (i.e., bacias sedimentares e plataformas) diversos. Em geral, três sucessões estratigráficas internas são reconhecidas, revelando sedimentação tipicamente descontínua. Assim, na base ocorre uma unidade com espessura média de $10 \mathrm{~m}$ (Figura 4), bem representada no litoral maranhense e subbacia de Cametá por arenitos e argilitos formados em ambientes litorâneos influenciados por correntes de maré. Esta unidade basal superpõe-se a depósitos de idade cretácea, sendo delimitada pela discordância que define a base do paleovale. Esta é caracterizada por superfície com relevo erosivo de até $40 \mathrm{~m}$ na escala de afloramento (ver DS1 na 

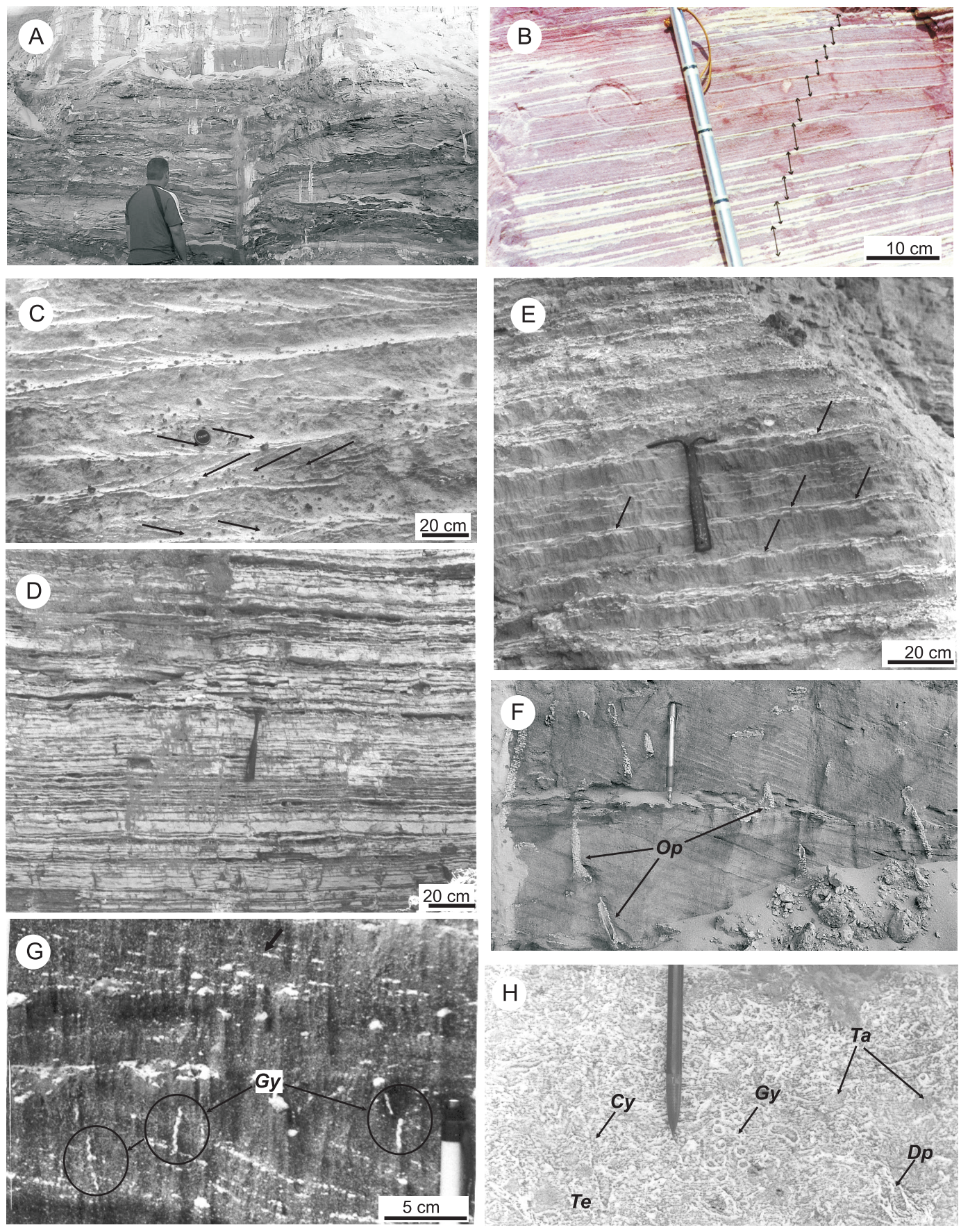

Figura 2. Feições sedimentares típicas dos depósitos miocênicos expostos no nordeste do Estado do Pará e litoral do Estado do Maranhão. A. Arenito com estratificação cruzada tabular. B. Estratos cruzados com foresets alternadamente mais espessos e mais delgados separados por filmes de argila, formando pares atribuídos à variação diurna de correntes de maré (setas). C. Estratos cruzados com abundantes superfícies de reativação revestidas com filmes de argila e contendo foresets bidirecionais (setas). D. Pacotes espessos com acamamentos heterolíticos. E. Acamamentos heterolíticos arranjados verticalmente formando camadas mais espessas e mais delgadas alternadamente, definidas por filmes de argila (setas). F, G e H. Tipos de icnofósseis que, no conjunto, caracterizam ambiente mixoalino, onde: $\mathbf{O p}=$ Ophiomorpha; $\mathbf{G y}=$ Gyrolithes; $\mathbf{T a}=$ Taenidium; $\mathbf{T e}=$ Teichichnus; $\mathbf{D p}=$ Diplocraterion; Cy = Cylindrichnus. 
(A)

(m) sW

20

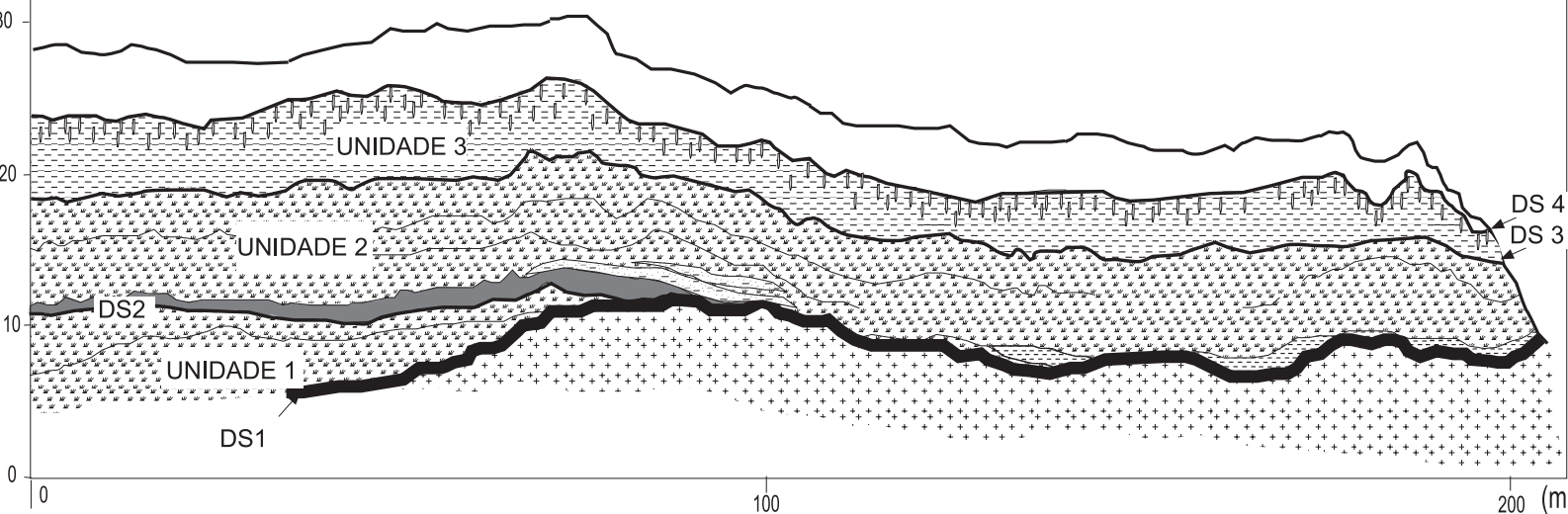

Delta de maré/leque de transbordamento

Planície de maré/mangue

Baía estuarina/laguna

Planície de maré/canal de maré?

Embasamento cretáceo

O Paleossolo laterítico

$\square$ Pós-Mioceno

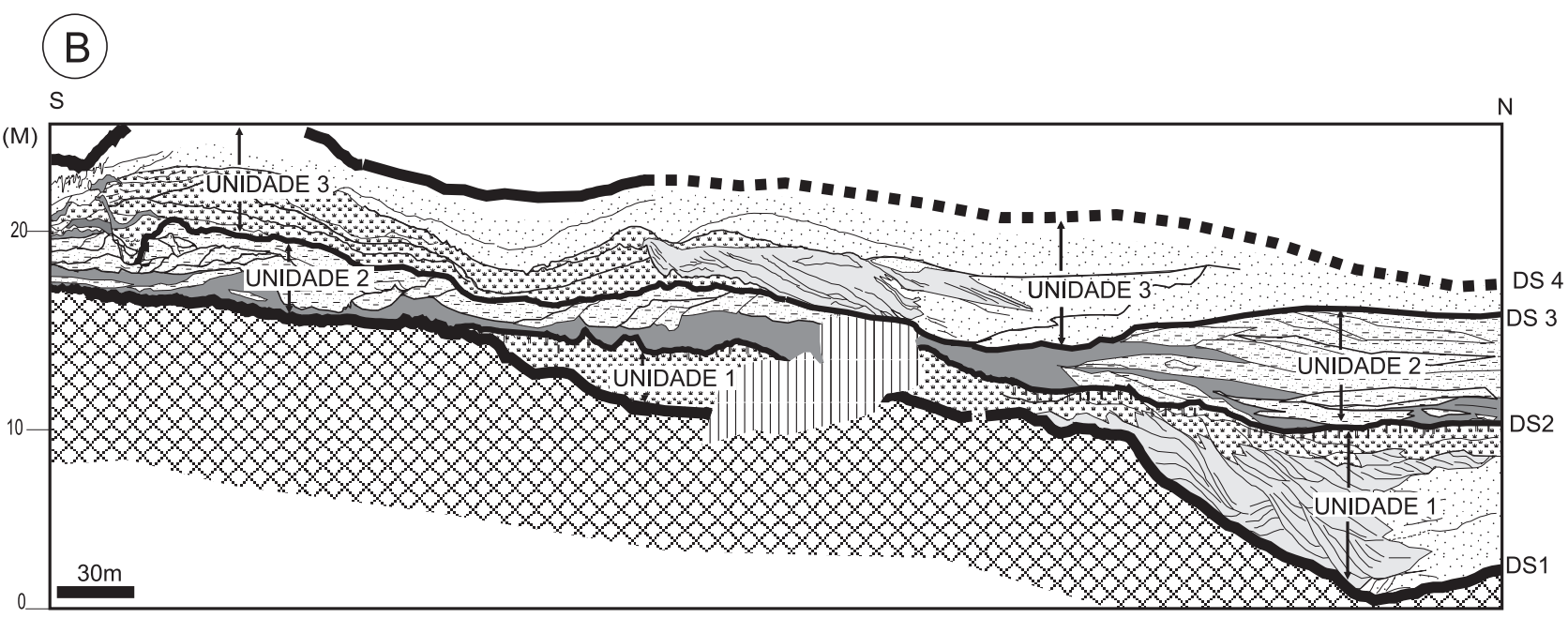

Canal de maré

Barra em pontal

Baía estuarina/laguna

Q Embasamento cretáceo
Delta de maré

Planície de maré/mangue/canal abandonado

Encoberto

Figura 3. Arquitetura dos estratos miocênicos no nordeste do Pará (A) e litoral do Maranhão (B), onde se observam três unidades estratigráficas (unidades 1 a 3 ) limitadas por diferentes tipos de superfícies de descontinuidades. DS1 e DS4. Discordâncias que delimitam os depósitos miocênicos. DS2 e DS3. Descontinuidades internas ao pacote miocênico. 
Figura 4), que se correlaciona lateralmente com superfície planar contendo horizonte de paleossolo laterítico/bauxítico com horizonte concrecionário tipicamente ramificado em padrão hexagonal. Esta superfície sintetiza cerca de $40 \mathrm{Ma}$ de não-deposição e/ou erosão, sendo possivelmente temporalmente correlacionável à superfície Sulamericana de King (1962), desenvolvida entre o final do Cretáceo e início do Terciário (Wijmstra, 1971; Lucas, 1989; Prasad, 1983; Truckenbrodt et al., 1995; Rossetti, 2004). O topo da unidade basal é definido por outra superfície de descontinuidade, que localmente mostra suave relevo erosivo e horizonte de paleossolo não-laterítico. Esta superfície é, ainda, bem marcada por icnofácies Glossifungites (ver DS2 na Figura 4), o que indica que, após período de exposição subaérea, as áreas em questão foram diretamente submetidas a transgressões marinhas, durante as quais elementos bentônicos tiveram a oportunidade de perfurar o substrato previamente depositado.

A unidade intermediária é de espessura similar e compreende quatro associações de fácies atribuídas a sistema de plataforma rasa a litorâneo transicional caracterizado por canal de maré, laguna e delta de maré enchente/leque de transbordamento, em parte representado por depósitos carbonáticos típicos da Formação Pirabas. Falésias locali- zadas ao longo do litoral do Estado do Maranhão são particularmente importantes para demonstrar a interdigitação lateral de depósitos das formações Pirabas e Barreiras (Rossetti, 2000). O topo da unidade intermediária é uma superfície de descontinuidade com relevo erosivo e, localmente, paleossolos, que pode formar amplas depressões côncavas para cima (ver DS3 na Figura 4).

A unidade superior é a mais espessa, podendo atingir até $24 \mathrm{~m}$ de espessura máxima (média de $9 \mathrm{~m}$ ) em escala de afloramento, sendo formada principalmente por depósitos de canais e planícies de maré, ocorrendo, ainda, depósitos de baía central estuarina, mangue e, para o topo, canal influenciado por sistema fluvial e planície de inundação. Seu topo é definido por uma discordância salientada por horizonte de solo laterítico contendo concreções ferruginosas, em geral sob forma de colunas verticalizadas de até $3 \mathrm{~m}$ de comprimento (ver DS4 na Figura 4 e na Figura 5). Esta superfície registra períodos de climas tropicais, com estações secas e úmidas bem definidas, que pode ter acompanhado o rebaixamento do nível eustático Tortoniano (Rossetti, 2001). Com isto, sugere-se correlação temporal com a superfície morfológica Velhas Superior, reconhecida em muitas outras áreas da América do Sul (p.ex., Aleva, 1981; Costa et al., 1997; Valenton, 1999).

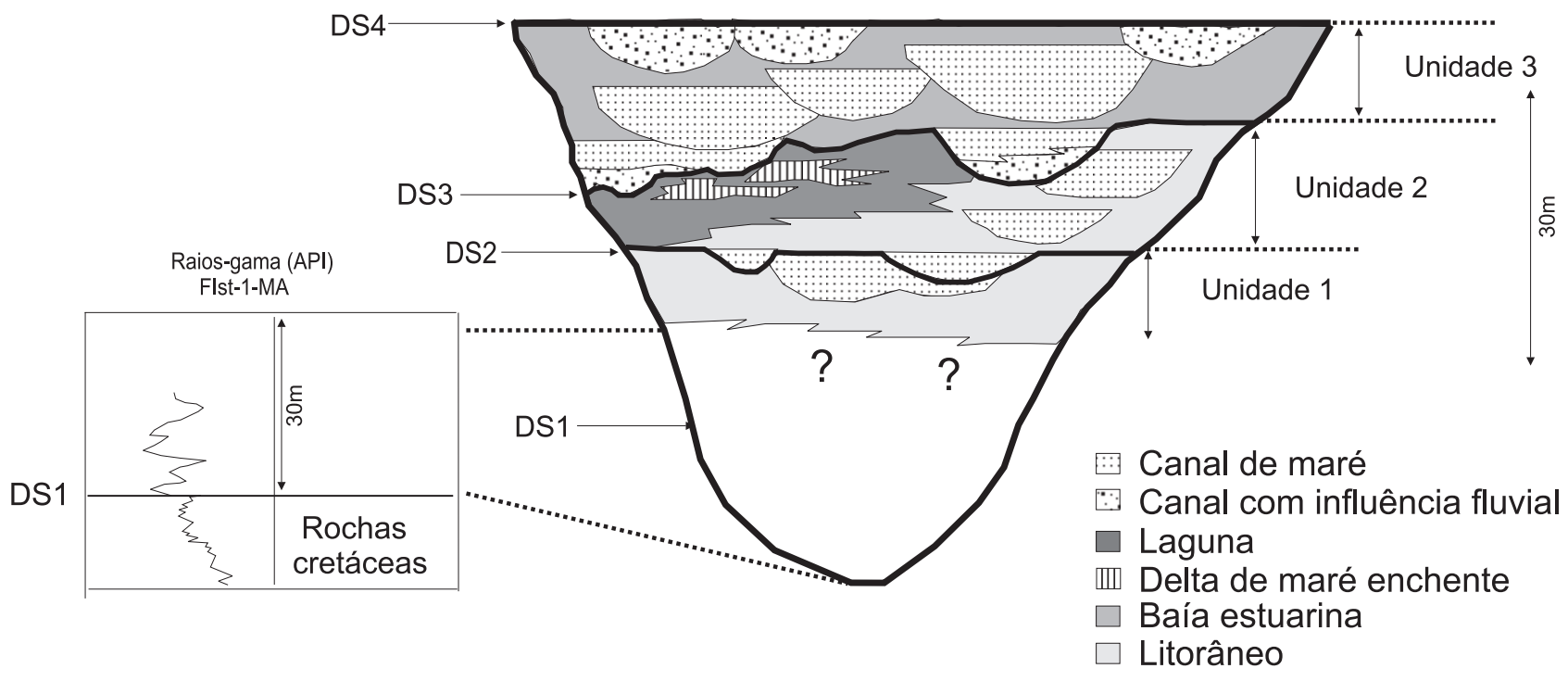

Figura 4. Desenho esquemático ilustrando o modelo deposicional proposto para os depósitos miocênicos expostos no nordeste do Pará e litoral do Maranhão, caracterizado por sistema de paleovales estuarinos incisos em depósitos cretáceos. 


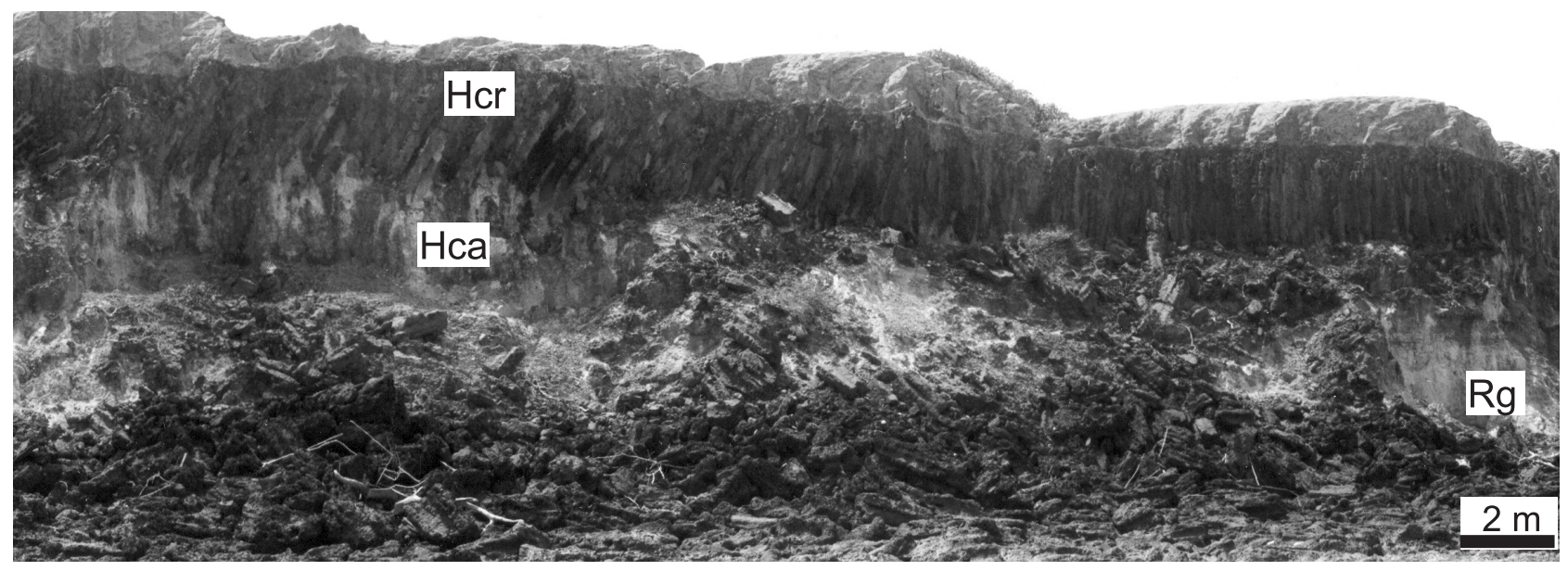

Figura 5. Detalhe da discordância do topo dos depósitos miocênicos no litoral do Maranhão, ilustrando perfil laterítico caracterizado por regolito $\mathbf{( R g}$ ) seguido para cima por horizonte caulinítico (Hca) e nível concrecionário (Hcr) formado por laterita ferruginosa em colunas verticais.

Com base na complexa organização interna, propõe-se que os depósitos miocênicos da região norte do Brasil foram depositados em um complexo de paleovales caracterizado por sistemas estuarinos com preenchimentos compostos (Rossetti, 2001; Rossetti e Santos Jr., 2004). Atribui-se que estes depósitos registram a passagem do trato de sistema transgressivo para condições de mar alto, conforme sugerido pelo caráter dominantemente progradante da sedimentação estuarina. A progradação não se processou de forma contínua, mas por meio de episódios múltiplos de variação do nível do mar de alta freqüência, superpostos a uma tendência principal de transgressão a mar alto.

Além da tendência geral transgressiva que marca o Eo/ Mesomioceno em várias regiões do globo como conseqüência de elevação eustática, tem-se sugerido que os estratos estuarinos da sucessão Pirabas/Barreiras reflitam a combinação deste fator com causa tectônica (Rossetti, 2006). Isto é evidenciado pelo fato dos paleovales estarem encaixados ao longo de zonas de falhas (Rossetti e Santos Jr., 2004; Rossetti, 2004, 2006). Feições deformacionais sinsedimentares, incluindo estruturas rúpteis e dúcteis associadas com a discordância basal do sistema de paleovale, bem como outras superfícies de descontinuidade internas a este, sustentam a origem e evolução com controle estrutural (Rossetti e Santos Jr., 2004; Rossetti, 2006).

\section{COMENTÁRIOS FINAIS E RECOMENDAÇÕES}

Os novos conceitos estratigráficos, refletidos no termo de seqüência deposicional (cf. Van Wagoner et al., 1990), definida por superfícies físicas em combinação com o arranjo arquitetural das fácies sedimentares, passaram a ser considerados critérios mais significativos que somente as características litológicas no estabelecimento do arcabouço estratigráfico e análise da evolução dos sistemas deposicionais. Em contraposição à caracterização litoestratigráfica, a aplicação deste procedimento de análise aos estratos miocênicos dos estados do Pará e Maranhão permitiu o reconhecimento de parâmetros importantes para a reconstituição dos ambientes deposicionais e entendimento de sua arquitetura estratal. Dada a natureza bastante pontual dos dados bioestratigráficos, esta ferramenta deve ser mais explorada futuramente na análise de outros depósitos miocênicos expostos ao longo da costa brasileira. Mesmo considerando-se o alto grau de intemperismo, é fundamental que um esforço integrado seja conduzido no sentido de caracterizar, em detalhes, as fácies sedimentares, procurando-se melhor definir os processos de sedimentação. A grande abundância de falésias costeiras distribuídas ao longo do litoral nordeste brasileiro disponibiliza um laboratório natural para a condução de investigações desta natureza. 
Além disto, a grande distribuição lateral destas exposições representa uma oportunidade ímpar para o mapeamento de possíveis superfícies de descontinuidade que possam ser de interesse estratigráfico. Tal procedimento poderá levar ao estabelecimento de critérios que possam vir a permitir a correlação dos estratos em escala interbacinal, além de ser crucial ao estabelecimento de modelos paleoambientais, pois possibilita a delimitação de fácies geneticamente relacionadas, imprescindível em quaisquer esforços visando-se reconstruções de sistemas deposicionais.

Considerando-se a tendência dominantemente transgressiva durante o Eo/Mesomioceno em escala global, as áreas continentais marginais estiveram sujeitas a freqüentes inundações marinhas. Estudos faciológicos detalhados mostram excelente registro de fases transgressivas nos estados do Pará e Maranhão, por meio do reconhecimento do domínio de sedimentação estuarina. Esta influência é registrada não só em depósitos localizados próximos à atual linha de costa, mas também é bem marcada em estratos situados a mais de $200 \mathrm{~km}$ dentro do continente (p.ex., Rossetti e Santos Jr., 2004). Possivelmente, o registro desta transgressão ocorreria também nas costas nordeste e sudeste do Brasil (Suguio e Nogueira, 1999). Apesar disto, não existe documentação de feições atribuídas a processos marinhos na Formação Barreiras exposta no litoral nordeste do Brasil. Uma possibilidade é a de que estes depósitos estejam hoje submersos na plataforma. Entretanto, considerando-se o intemperismo acentuado desses estratos, nem sempre é possível se proceder com análise faciológica que permita a adequada reconstituição dos processos sedimentares. A título de comparação, vale ressaltar que os estudos sistemáticos realizados nos depósitos aqui documentados mudaram a concepção tradicional de que a Formação Barreiras dos estados do Pará e Maranhão são tipicamente não estruturados, e de origem fluvial, como comumente descritos na literatura (p.ex., Góes e Truckenbrodt, 1980; Góes, 1981). Embora em muitos locais o forte intemperismo tenha contribuído para obliterar, em parte ou totalmente, as estruturas sedimentares, trabalhos de campo sistemáticos serviram para detectar uma abundância de excelentes exposições onde estudos faciológicos possibilitaram uma reconstituição bastante refinada dos processos sedimentares e ambientes de deposição. É possível que um estudo faciológico sistemático em áreas onde estes estratos estejam melhor preservados, particularmente ao longo de falésias litorâneas, possa fornecer novas informações para se interpretar mais adequadamente os ambientes de deposição formados durante o Mioceno ao longo da costa brasileira.

Dentro deste contexto, e dada a carência de informações paleontológicas na Formação Barreiras, ressalta-se a importância de se proceder com uma análise faciológica acompanhada de detalhado estudo icnológico. Apesar da pre- sença freqüente, infelizmente o registro de icnofósseis nestes estratos é ainda bastante limitado, merecendo estudos mais sistemáticos para sua aplicação como ferramenta adicional na reconstrução das condições de deposição.

Ressalta-se, como comentário final, a importância de reativações tectônicas no desenvolvimento do sistema de paleovales estuarinos miocênicos registrado na região norte do Brasil. O desenvolvimento destes paleovales foi crucial para que pelo menos parte dos registros sedimentares fosse preservada e utilizada na reconstituição da história geológica miocênica. Vale mencionar que, apesar de sucessivas elevações do nível do mar entre o final do Cretáceo e o Mioceno, a discordância basal do sistema de paleovales miocênicos registra um período de aproximadamente $40 \mathrm{Ma}$ de não-deposição e/ou erosão, que se processou provavelmente quando a área manteve-se tectonicamente estável. Somente com reativações de falhas no Terciário Médio (Costa et al., 1993, 1995; Costa e Hasui, 1997), houve condições favoráveis à formação de áreas subsidentes, onde a preservação do registro sedimentar do Mioceno foi favorecida.

\section{AGRADECIMENTOS}

À FAPESP, pela concessão de auxílio (Projeto \#004/15518-6), que possibilitou a elaboração de parte desta pesquisa. Ao Dr. Mário Ferreira de Lima Filho e um revisor anônimo, pelas valiosas sugestões e correções que contribuíram para melhorar a versão final do manuscrito.

\section{REFERÊNCIAS BIBLIOGRÁFICAS}

ALEVA, G. J. J. Bauxitic and other duricrusts on the Guiana Shield, South America. In: BANERJI, P. K. (Ed.) Laterisation Processes. INTERNATIONAL SEMINAR ON LATERISATION PROCESSES, 1., 1981, Oxford. Proceeding... Oxford: Oxford \& IBH Publishers, 1981. p. 261-269.

AMADOR, E. S. Depósitos relacionados à unidade inferior do Grupo Barreiras no Estado do Espírito Santo. In: CONGRESSO BRASILEIRO DE GEOLOGIA, 23., 1982, Salvador. Anais... Salvador: Sociedade Brasileira de Geologia, 1982. p. 1451-1461.v. 4.

ARAI, M. Dinoflagelados (Dynophiceae) miocênicos do Grupo Barreiras do nordeste do Estado do Pará (Brasil). Revista Universidade de Guarulhos, n. 2, p. 98-106, 1997.

ARAI, M.; UESUGUI, N.; ROSSETTI, D. F.; GÓES, A. M. Considerações sobre a idade do Grupo Barreiras no nordeste do Estado do Pará. In: CONGRESSO BRASILEIRO DE GEOLOGIA, 35., 1988, Belém. Anais... Belém: Sociedade Brasileira de Geologia, 1988. p. 738-752. v. 2. 
ARANTES, J. L. G.; DAMASCENO, B. C.; KEBRS, A. S. J. Projeto Argila. Belém: DNPM/CPRM, 1972.40 p. (Relatório técnico).

AZEVEDO, R. P. Tectonic evolution of Brazilian Equatorial Continental Margin Basins. 1991. 455 f. Tese (Doutorado) - University of London, Londres, 1991.

BEMERGUY, R. L. Morfotectônica e evolução paleogeográfica da região da calha do Rio Amazonas. 1997. $200 \mathrm{f}$. Tese (Doutorado) - Universidade Federal do Pará, Belém, 1997.

BERMEGUY, R. L.; COSTA, J. B. S. Considerações sobre o sistema de drenagem da Amazônia e sua relação com o arcabouço tectono-estrutural. Boletim Paraense Emílio Goeldi (Série Ciências da Terra), v. 3, p.75-97, 1991.

CARVALHO, P. F. Reconhecimentos geológicos entre a costa atlântica e Pirabas e a estação experimental na estrada de ferro de Bragança. Boletim do Serviço Geológico e Mineralógico, v. 15, p. 115-124, 1926.

COSTA, J. B. S.; HASUI, Y. Evolução geológica da Amazônia. In: COSTA, M. L.; ANGÉLICA, R. S. (Ed..) Contribuições à geologia da Amazônia. Belém: SBG, 1997. p. 15-19.

COSTA, J. B. S.; BORGES, M. S.; BEMERGUY, R. L.; FERNANDES, J. M. G.; COSTA JR., P. S.; COSTA, M. L. A evolução cenozóica da região de Salinópolis, nordeste do Estado do Pará. Geociências (UNESP), v. 12, n. 2, p. 373-396, 1993.

COSTA, J. B. S.; HASUI, Y.; BORGES, M. S.; BEMERGUY, R. L. Arcabouço tectônico mesozóico-cenozóico da região da calha do Amazonas. Geociências (UNESP), 14, n. 2, p. 77-83, 1995 .

COSTA, J. B. S.; BEMERGUY, R. L.; HASUI, Y.; BORGES, M. S.; FERREIRA JR., C. R .P.; BEZERRA, P. E. L.; COSTA, M. L.; FERNANDES, J. M. G. Neotectônica da região amazônica: aspectos tectônicos, geomorfológicos e deposicionais. Geonomos, v. 4, n. 2, p. 23-43, 1996.

COSTA, M. L.; HORBE, A. M. C.; MORAES, E. L. Lateritização imatura sobreposta a lateritos maturos em Mão do Rio, Estado do Pará. In: COSTA, M. L.; ANGÉLICA, R. S. (Ed.) Contribuições à geologia da Amazônia, Belém: SBG, 1997. p. 339-359.

COSTA, J. B. S.; HASUI, Y.; BEMERGUY, R. L.; VILLEGAS, J. M. C. Tectonics and paleogeography of the Marajó Basin, northern Brazil. Anais da Academia Brasileira de Ciências, 74, n. 3, p. 519-531, 2002.

FERNANDES, J. M. G. Paleoecologia da Formação Pirabas, Estado do Pará. In: CONGRESSO BRASILEIRO DE GEOLOGIA, 33.,1984, Rio de Janeiro. Anais...Rio de Janeiro: Sociedade Brasileira de Geologia, 1984, p. 84-88. v. 1.

FERREIRA, C. S. Contribuição à paleontologia do Estado do Pará - um novo Xancus da Formação Pirabas. VII (Mollusca-Gastropoda). Boletim do Museu Paraense Emílio Goeldi (Série Geologia), v. 10, p. 1-8, 1964.

FERREIRA, C. S. Características lito-paleontológicas na Formação Pirabas, estado do Pará. In: CONFERÊNCIA GEOLÓGICA DAS GUIANAS, 6., 1966, Belém. Anais... Belém: Departamento Nacional de Produção Mineral, 1966. p. 101-111, v. 6 .

FERREIRA, C. S. Notas estratigráficas sobre o Cenozóico marinho do Estado do Pará. In: SIMPÓSIO DE GEOLOGIA DAAMAZÔNIA, 1., 1982, Belém. Anais... Belém: Sociedade Brasileira de Geologia, 1982. p. 84-88, v. 1.

FERREIRAJR., C. R. P.; COSTA, J. B. S.; BEMERGUY, R. L.; HASUI, Y. Neotectônica na região da Bacia de São Luís. Geociências (UNESP), v. 15, p. 185-208, 1996.

FERREIRA, C. S.; VICALVI, M. A.; MACEDO, A. C. M. Os limites meridionais da Bacia de Pirabas. In: CONGRESSO BRASILEIRO DE GEOLOGIA, 33., 1984, Rio de Janeiro. Anais...Rio de Janeiro: Sociedade Brasileira de Geologia, 1984.p. 326-329, v. 1.

GALVÃO, M. V. G. Evolução termodinâmica da Bacia do Marajó, Estado do Pará, Brasil. 193f. 1991.Dissertação (Mestrado) - Departamento de Geologia, Universidade Federal de Ouro Preto, Ouro Preto, 1991.

GÓES A. M. Estudo sedimentológico dos sedimentos Barreiras, Ipixuna e Itapecuru, no nordeste do Estado do Pará e noroeste do Maranhão. 1981. 55 f. Dissertação (Mestrado) - Universidade Federal do Pará, Belém, 1981.

GÓES, A. M.; ROSSETTI, D. F. Gênese da Bacia de São Luís-Grajaú. In: ROSSETTI, D. F.; GÓES, A. M.; TRUCKENBRODT, W. (Ed.) O Cretáceo da Bacia de São Luís-Grajaú, Belém: MPEG Editoração, 2001.p. 15-29.

GÓES, A. M.; TRUCKENBRODT, W. Caracterização faciológica e interpretação ambiental dos sedimentos Barreiras na região bragantina, nordeste do Pará. In: CONGRES- 
SO BRASILEIRO DE GEOLOGIA, 31., 1980, Camburiú. Anais...Camburiú: Sociedade Brasileira de Geologia, 1980. p. 766-771, v. 2.

GÓES, A. M.; ROSSETTI, D. F.; NOGUEIRA, A. C. R.; TOLEDO, P. M. Modelo deposicional preliminar da Formação Pirabas no nordeste do Estado do Pará. Boletim do Museu Paraense Emílio Goeldi (Série Ciências da Terra), v. 2, p. 3-15, 1990.

HASUI, Y. Neotectônica e aspectos fundamentais da tectônica ressurgente no Brasil. In: WORKSHOP SOBRE NEOTECTÔNICAE SEDIMENTAÇÃOCENOZÓICACONTINENTAL NO SUDESTE BRASILEIRO, 1., 1990, Belo Horizonte. Boletim...Belo Horizonte: Sociedade Brasileira de Geologia, 1990. p. 1-31, n. 11.

IGREJA, H. L. S. Aspectos tectono-sedimentares do fanerozóico do nordeste do Estado do Pará e noroeste do Maranhão. 1992. 192f. Tese (Doutorado) - Universidade Federal do Pará, Belém, 1992.

IGREJAH. L. S.; BORGES M. S.; ALVES, R. J.; COSTAJR., P. S. C.; COSTA, J. B. S. Estudos neotectônicos nas ilhas de Outeiro e Mosqueiro, NE do Estado do Pará. In: CONGRESSO BRASILEIRO DE GEOLOGIA, 36., 1990, Natal. Anais... Natal: Sociedade Brasileira de Geologia, 1990. p. 2110-2123, v. 5.

KATZER, F. Geologia do Estado do Pará (Brasil). Boletim do Museu Paraense Emílio Goeldi, n. 9, p. 1-269, 1933.

KING, L. C. The Morphology of the Earth. Edinburg: Oliver \& Boyd, 1962.

LEITE, F. P. R.; OLIVEIRA, M. E. B.; OLIVEIRA, P. E.; SILVESTRE-CAPELATO, M.S.;ARAI, M.;TRUCKENBRODT, W. Palinofloras miocenas da Formação Pirabas e Grupo Barreiras, na Região Bragantina, Estado do Pará, Brasil. Revista da Universidade de Guarulhos (Geociências), v. 2, p. 128-140, 1997a. Número especial.

LEITE, F. P. R.; OLIVEIRA, M. E. B.; ARAI, M.; TRUCKENBRODT, W. Palinoestratigrafia da Formação Pirabas e Grupo Barreiras, Mioceno do nordeste do estado do Pará, Brasil. Revista da Universidade de Guarulhos (Geociências), v. 2, p. 141-147, 1997b. Número especial.

LUCAS, Y. Systèmes pédologiques em Amazonie Brésilienne - equilibres, desequilibres et transformations. 1989. 158 f. Tese (Doutorado) - University of Poitiers, Poitiers, 1989.
MONTANARI, A.; ODIN, G. S.; COCCIONI, R. Miocene Stratigraphy: an integrated approach Amsterdam: Elsevier, 1997. 694 p. (Developments in Palaeontology and Stratigraphy, 15).

MUSSA, D. Dicotiledôneo fóssil da Formação Barreiras, Estado do Sergipe, Brasil. Boletim Departamento Nacional da Produção Mineral, Divisão de Geologia e Mineralogia, v. 181, p. 1-23, 1958.

NETTO, R. G.; ROSSETTI, D. F. Ichnology and salinity fluctuations: a case study in the Early Miocene (Lower Barreiras Succession) of São Luís Basin, Maranhão, Brazil. Revista Brasileira de Paleontologia, n. 6, p. 5-18, 2003.

OLIVEIRA, A. J.; LEONARDOS, O. H. Geologia do Brasil. 2. ed. Rio de Janeiro: Ministério da Agricultura, 1943. 813 p.

PENNA, D. S. Breve notícia sobre os sambaquis do Pará. Arquivos do Museu Nacional, v. 1, p. 85-99, 1876.

PETRI, S. Foraminíferos fósseis da Bacia do Marajó. Boletim da Faculdade de Filosofia, Ciências e Letras da Universidade de São Paulo (Geologia), v. 134, 1-172, 1954.

PETRI, S. Foraminíferos miocênicos da Formação Pirabas. Boletim da Faculdade de Filosofia, Ciências e Letras da Universidade de São Paulo (Geologia), v. 216, n. 16, p. 1-79, 1957.

PRASAD, G. A review of the early Tertiary bauxite event in South America, Africa and India. Journal of African Earth Sciences, v. 1, n. 3-4, p. 305-313, 1983.

ROSSETTI, D. F.; GÓES, A. M.; TRUCKENBRODT, W. A influência marinha nos Sedimentos Barreiras. Boletim do Museu Paraense Emílio Goeldi (Série Ciências da Terra), v. 2, n.1, p. 17-29, 1990.

ROSSETTI, D. F. Influence of low amplitude/high frequency relative sea-level changes in a wave-dominated estuary (Miocene), São Luís Basin, northern Brazil. Sedimentary Geology, 133, n. 3-4, p. 295-324, 2000.

ROSSETTI, D. F. Late Cenozoic sedimentary evolution in northeastern Pará, Brazil, within the context of sea level changes. Journal of South American Earth Sciences, 14, n. 1, p. 77-89, 2001.

ROSSETTI, D. F. Paleosurfaces from northeastern Amazonia as a key for reconstructing paleolandscapes and understanding weathering products. Sedimentary Geology, 
v. 169, n. 3-4, p. 151-174, 2004.

ROSSETTI, D. F. The role of tectonics on the preservation of Estuarine Valleys in areas with Low Accommodation Rates: examples from Upper Cretaceous and Miocene Successions in Northern Brazil. In: INCISED-Valley Systems in Time and Space. Tulsa, Okla: SEPM (Society for Sedimentary Geology SEPM, 2006. (Special Publication, no prelo).

ROSSETTI, D. F.; GÓES, A. M. Geologia. In: ROSSETTI, D. F.; GÓES, A. M. (Eds.) O Neógeno da Amazônia Oriental. Belém: Museu Paraense Emílio Goeldi, 2004. p. 13-52.

ROSSETTI, D. F.; SANTOS JR., A. E. A. Facies architecture in a tectonically-influenced estuarine incised valley fill of Miocene age, Northern Brazil. Journal of South America Earth Sciences, v. 17, n. 4, p. 267-284, 2004.

ROSSETTI, D. F.; TRUCKENBRODT, W.; GÓES, A. M. Estudo paleoambiental e estratigráfico dos sedimentos Barreiras e Pós-Barreiras na região bragantina, nordeste do Pará. Boletim do Museu Paraense Emílio Goeldi (Série Ciências da Terra), v. 1, p. 25-74, 1989.

ROSSETTI, D. F.; GÓES, A. M.; TRUCKENBRODT, W. A influência marinha nos Sedimentos Barreiras. Boletim do Museu Paraense Emílio Goeldi (Série Ciências da Terra), v. 2, p. 17-29, 1990.

SÁ, J. H. S. Contribuições à geologia dos sedimentos terciários e quaternários da região bragantina. Boletim do Instituto de Geologia, v. 3, p. 21-36, 1969.

SUGUIO, K.; NOGUEIRA, A. C. R. Revisão crítica dos conhecimentos geológicos sobre a Formação (ou Grupo?) Barreiras do Neógeno e o seu possível significado como testemunho de alguns eventos geológicos mundiais. Geociências, Rio Claro, v. 18, n. 2, p. 461-479, 1999.

TÁVORA, V. A.; SILVA JR., O. G. Icnofósseis da Formação Pirabas (Eomioceno) na baía de Inajá-Estado do Pará. Revista Brasileira de Paleontologia, v. 2, p. 163, 2001.

TRUCKENBRODT,W.; KOTSCHOUBEY,B.;HIERONYMUS, B. Aluminization: an important process in the evolution of Amazonian bauxites. Tav. ICSOBA, n. 2, p. 27-42, 1995.

VALENTON, I. Saprolite-bauxite fácies of ferralitic duricrusts on palaeosurfaces of former Pangaea. In: THIRY, M.; SIMONCoinçon, R. (Eds.). Palaeoweathering, palaeosurfaces and related Continental Deposits. Oxford: International
Association of Sedimentologists, 1999. p. 87-129. (Special Publication, 27).

VAN WAGONER, J. C.; MITCHUM, R. M.; CAMPION, K. M.; RHAMANI, V. D. Siliciclastic Sequence Stratigraphy in Well Logs, Cores and Outcrops: concepts for high resolution correlation of time and facies. Tulsa: American Association of Petroleum Geologists, 1990.55p. (Methods in Exploration Series, 7).

WIJMSTRA, T. A. The palynology of the Guiana coastal basin. 1971. 62f. Tese (Doutorado) - University of Amsterdam, Amsterdam, 1971.

ZAITLIN, B. A.; DALRYMPLE, R. W.; BOYD, R.; LECKIE, D. The stratigraphic organization of Incised Valley Systems: implications to hydrocarbon exploration and production with examples from the western Canada Sedimentary Basin. Calgary: Canadian Society of Petroleum Geology, Calgary, 1994. $260 \mathrm{p}$. 